\title{
Modelling and optimization of machining parameters during hardened steel AISID3 turning using RSM, ANN and DFA techniques: Comparative study
}

\author{
L. Bouzid ${ }^{1,2}$, M.A. Yallese ${ }^{1}$, S. Belhadi' ${ }^{1}$ and A. Haddad ${ }^{3}$ \\ ${ }^{1}$ Laboratoire Mécanique et Structure (LMS), Université 8 Mai 1945, Guelma, Algeria \\ ${ }^{2}$ Department of Mechanical Engineering, University Labri Ben M'Hidi Oum el Bouaghi, Oum El Bouaghi, Algeria \\ ${ }^{3}$ Laboratoire de Mécanique Appliquée des Nouveaux Matériaux (LMANM), Université 8 Mai 1945, Guelma, Algeria
}

ABSTRACT - Nowadays, the relationships linking the cutting conditions to the different technological parameters are becoming a major industrial objective. The present work deals with some machinability investigations involving surface roughness and cutting force in finish turning of AISI D3-hardened steel using carbide, ceramic and coated ceramic inserts. The combined effects of the cutting parameters represented by the cutting depth (ap), the cutting tool (Tool), the cutting speed $(V c)$, and the feed rate $(f)$ on the output parameters illustrated by both the surface roughness $(R a)$ and the cutting force $(F y)$ are investigated using the analysis of variance (ANOVA). The modelling of surface roughness and cutting force is carried out using both Response Surface Methodology (RSM) and Artificial Neural Network (ANN). In order to determine the most efficient technique, the models developed are compared in terms of the coefficient of determination $\left(R^{2}\right)$, the Root Mean Square Error (RMSE) and the Model Predictive Error (MPE). Furthermore, a multiobjective optimization using the Desirability Function Analysis (DFA) has been performed. The obtained results show that the ANN models (For Ra: $R^{2}=93 \%, R M S E=0.02 \%, M P E=4.99 \%$ and for Fy: $R^{2}=94 \%, R M S E=2.52 \%, M P E=3.11 \%$ ) performed better than those developed using the RSM approach (For $R a: R^{2}=90.4 \%, R M S E=0.051 \%, M P E=18.21 \%$ and for $F y: R^{2}=79 \%, R M S E=31.17 \%$, $M P E=55.92 \%)$. As a consequence, the achieved ANN models for $(R a)$ and $(F y)$ are exploited as objective function for the response optimization applying the DFA technique. The optimum level of the input parameters for the combined desirability is finally identified as ap1-Too/3-Vc3-f1 for both $(R a)$ and $(F y)$ with a maximum error of $2.94 \%$.

\author{
ARTICLE HISTORY \\ Revised: 29th Dec 2019 \\ Accepted: 1st Mar 2020
}

\section{KEYWORDS}

Modelling;

optimization;

response surface methodology;

artificial neural network; desirability function

analysis.

\section{INTRODUCTION}

The economic aim of the manufacturing costs along with the technical requirements of the machining of hard materials requires an overall control and an optimization of the manufacturing processes. Compared to the classical experimental methods, the use of statistical approaches and artificial intelligence (AI)-based models such as artificial neural network models are leading the way to achieving technically and economically credible processes of efficient predetermination $[1,2]$. $n$ manufacturing processes, the integrity of a surface finish is of great importance to describe the quality of the work piece. Therefore, the surface roughness is an important technological parameter that characterizes the quality of a product and a criterion that greatly influences the manufacturing cost [3-5]. Furthermore, it should be mentioned that during the cutting of metal material, cutting power and dimensional accuracy are both influenced by the evolution of the cutting force components $[6,7]$.

Several studies have been carried aiming to compare the predictive power of mathematical models resulting from various methods, particularly the RSM and ANN approaches when turning different materials.

Tebassi et al [8] introduced predictive models involving both surface roughness and cutting force developed using both ANN and RSM methods when turning Inconel 718 with a coated carbide tool. The results showed that the (ANN) approach is very effective in detecting non-linear responses. The comparison was carried out in terms of the coefficient of determination $\left(R^{2}\right)$, Root Mean Square Error $(R M S E)$ and Model Predictive Error $(M P E)$.

Chabbi et al [2] nvestigated the influence of cutting parameters on surface roughness, cutting forces, cutting power and productivity during polymer turning (POM C). Both RSM and ANN modelling techniques were used. The comparison resulted in finding greater values of $\left(R^{2}\right)$ for ANN than those of RSM, demonstrating the robustness and reliability of the ANN method.

A comparative study involving the development of models for surface roughness $(R a)$, tangential stress $(F y)$, power $(P c)$ and material removal rate $(M R R)$ obtained by both ANN and RSM approaches when turning EN-GJL-250 cast iron using a composite ceramic was performed by Laouissi et al [9]. The predictive capabilities of the ANN and RSM models were compared in terms of the Mean Absolute Deviation (MAD), the Mean Absolute Percentage Error (MAPE), the Root 
Mean Square Error $(R M S E)$ and the coefficient of determination $\left(R^{2}\right)$. They identified the ANN approach as more accurate than RSM approach.

Zerti et al [10] considered the impact of the machining parameters ( $V c$, ap and $f$ ) on the surface roughness criteria ( $R a$, $R z$ and $R t)$ as well as on the cutting force components ( $F x, F y$ and $F z$ ) when dry turning martensitic stainless steel (AISI 420) treated at $59 \mathrm{HRC}$. Both the RSM and ANN approaches were applied to develop predictive models. Comparison between the experimental and predicted results in terms exhibited errors of the ANN models in the range of $(0.01 \%$ $5.62 \%)$ for $(R a)$ and $(0.02 \%-3.99 \%)$ for $(F z)$. The errors pertaining to the models developed by RSM were found to be significantly lower i.e. $3.85 \%-67.09 \%$ for $(R a)$ and $0.19 \%-20.58 \%$ for $(F z)$. Similar results were achieved by Nouioua et al [11] when turning X210Cr12 steel, in a MQL, dry, and lubricated environments.

Numerous other researchers identified the RSM approach as better than the ANN. Kumar and Chauhan [12] for example investigated the shooting of the hybrid composites A17075/10/SiCp and A17075. They concluded that the ANN prediction model produced larger errors than MSR with $\left(R^{2}\right)$ reaching 0.9957 and 0.9972 respectively.

The present investigation starts by modelling the surface roughness $(R a)$ and cutting force $(F y)$ using both RSM and ANN methods. A comparative study is later carried out between the two approaches in terms of the coefficient of determination, the root mean square error and the model predictive error in order to determine the most efficient. An optimization of the cutting conditions using DFA approach is finally performed by applying the best identified model (RSM or ANN) as objective function.

\section{EXPERIMENTAL SETUP AND PROCEDURE}

\section{Material, Inserts and Experimental Design}

Figure 1 displays the flow chart pertaining to the experimental procedure according to the response surface methodology (RSM). Four essential steps are adopted [13, 14].

Step (1) conducting experiments: It mainly consists in designating the input parameters, their level of importance and adopting the appropriate experimental design. In this study, the cutting speed along with the feed, the depth of cut and insert material have been adopted as input process machining parameters, whereas both the surface roughness and cutting force were selected as the responses. The parameters and their corresponding levels are illustrated in Table 1. For the sequence of experimentation, a design matrix was developed in correspondence with Taguchi design of experiments. It comprises (18) experimental runs integrating the selected four parameters along with three levels. Table 2 presents the experimental input details and results.

Table 1. Process parameters and levels

\begin{tabular}{c|c|c|c|c}
\hline Levels & $\begin{array}{c}V c \\
(\mathrm{~m} / \mathrm{min})\end{array}$ & $\begin{array}{c}f \\
(\mathrm{~mm} / \mathrm{rev})\end{array}$ & Tool & ap $(\mathrm{mm})$ \\
\hline 1 & 100 & 0.08 & 1 & 0.25 \\
\hline 2 & 200 & 0.14 & 2 & 0.5 \\
\hline 3 & 300 & 0.2 & 3 & $/$ \\
\hline \multicolumn{4}{|c}{ Tool $: 1-(\mathrm{GC5015)} ; 2-($ CC6050) $; 3-($ CC650) } \\
\hline
\end{tabular}

Table 2. Experimental design and results

\begin{tabular}{c|cccc|cc}
\hline \multirow{3}{*}{ Runs } & \multicolumn{3}{|c|}{ Machining parameters } & \multicolumn{2}{c}{ Responses } \\
\cline { 2 - 7 } & $\begin{array}{c}\text { ap } \\
(\mathrm{mm})\end{array}$ & Tool & $\begin{array}{c}\text { Vc } \\
(\mathrm{m} / \mathrm{min})\end{array}$ & $\begin{array}{c}f \\
(\mathrm{~mm} / \mathrm{rev})\end{array}$ & $\begin{array}{c}\text { Ra } \\
(\mu \mathrm{m})\end{array}$ & $\begin{array}{c}F y \\
(\mathrm{~N})\end{array}$ \\
\hline 1 & 0.25 & 1 & 100 & 0.08 & 0.505 & 314.07 \\
2 & 0.25 & 1 & 200 & 0.14 & 1.035 & 373.64 \\
3 & 0.25 & 1 & 300 & 0.2 & 2.38 & 606.99 \\
4 & 0.25 & 2 & 100 & 0.08 & 0.32 & 185.82 \\
5 & 0.25 & 2 & 200 & 0.14 & 0.91 & 230.88 \\
6 & 0.25 & 2 & 300 & 0.2 & 1.82 & 261.39 \\
7 & 0.25 & 3 & 100 & 0.14 & 1.135 & 99.47 \\
8 & 0.25 & 3 & 200 & 0.2 & 1.715 & 128.55 \\
9 & 0.25 & 3 & 300 & 0.08 & 0.42 & 81.86 \\
10 & 0.5 & 1 & 100 & 0.2 & 2.855 & 782.99 \\
11 & 0.5 & 1 & 200 & 0.08 & 0.57 & 561.36 \\
12 & 0.5 & 1 & 300 & 0.14 & 1.26 & 1300.43 \\
13 & 0.5 & 2 & 100 & 0.14 & 0.98 & 323.76
\end{tabular}




\begin{tabular}{c|cccc|cc}
14 & 0.5 & 2 & 200 & 0.2 & 1.79 & 379.72 \\
15 & 0.5 & 2 & 300 & 0.08 & 0.41 & 259.22 \\
16 & 0.5 & 3 & 100 & 0.2 & 1.31 & 186.8 \\
17 & 0.5 & 3 & 200 & 0.08 & 0.41 & 132.57 \\
18 & 0.5 & 3 & 300 & 0.14 & 0.895 & 161.39 \\
\hline
\end{tabular}

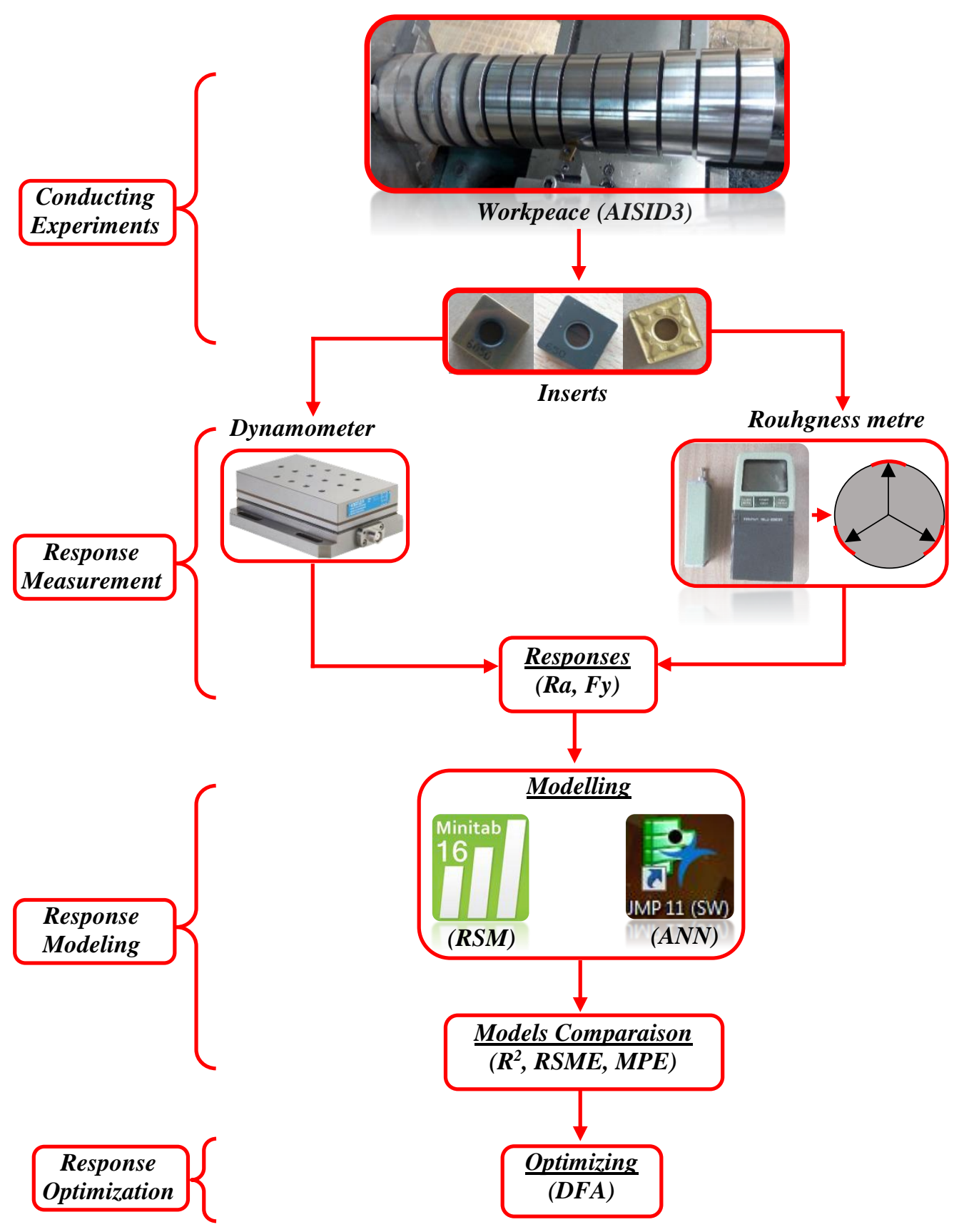

Figure 1. Schematic diagram of the experimental procedure and methodology.

The experiments were performed using high alloyed steel AISI D3 in round bar having $74 \mathrm{~mm}$ in diameter and 380 $\mathrm{mm}$ in length. AISI D3 is a tool steel that integrates a high proportion of chromium (12\%) and presents a minimum risk of deformation and alteration of dimensions in heat treatments. Because of its excellent wear and high cutting resistances, it is widely employed in many applications such as high performance cutting tools, deburring or slitting tools, cutting tools for paper and plastics, stamping tools, and woodworking tools [15]. The experiments were performed on a lathe machine model SN40C exhibiting a spindle power of $6.6 \mathrm{~kW}$. Table 3 summarizes the elemental composition of the work piece material in terms of weight percentage. Ceramic tools inserts reference CC6050 and CC650 along with carbide 
reference GC4015 were used to machine the AISI D3 steel with a geometry represented by a rake angle of $6^{\circ}$, a clearance angle of $6^{\circ}$ and an approach edge of $75^{\circ}$.

Table 3. Elemental composition of AISI D3 steel (wt\%).

\begin{tabular}{c|c|c|c|c|c|c|c|c|c}
\hline$C$ & $C r$ & $M n$ & $S i$ & $P$ & $C u$ & $M o$ & $N i$ & $S$ & $V$ \\
\hline $2 \div 2.35$ & $11 \div 13.5$ & 0.6 & 0.6 & 0.03 & 0.25 & 0.20 & 0.3 & 0.03 & 1 \\
\hline
\end{tabular}

Step (2) response measurement: For each cutting condition, the instantaneous measurements of the surface roughness $(R a)$ are performed using a Mitutoyo Surftest 201 roughness meter. The length examined is $4 \mathrm{~mm}$ with a cut-off of 0.8 $\mathrm{mm}$. In order to reduce uncertainties due to rework operations, the roughness is measured directly on the workpiece without dismounting the lathe. The measurements are repeated three times on the surface of the workpiece with three reference lines positioned at $120^{\circ}$ (figure1), the final result represented by the average of these measurements. In order to measure the cutting force, the tool holder is mounted on a three-component piezoelectric dynamometer (Kistler 9257B) allowing measurements from $-5 \mathrm{kN}$ to $5 \mathrm{kN}$. The measurement chain includes a charge amplifier (Kistler 5019B130) data acquisition hardware (A/D 2855A3) and a graphical programming environment (Dynoware 2825A1-1) for data analysis and visualization.

Step (3) response modeling: It deals with the development of the prediction models for the surface roughness ( $R a$ ) and cutting force $(F y)$. Both the response surface methodology and artificial neural networks modeling techniques were used. Two statistical software namely Minitab-16 and JMP-11 were used for the analysis of the data. In order to select the best model that will be used later as an objective function for the optimization procedure, a comparison between the models developed is performed in terms of $R^{2}, R M S E$ and MPE.

Step (4) response optimization: The best mathematical model derived in the previous step is herein used as an objective function for the optimization process. The desirability Function Approach (DFA) is applied.

\section{RESULTS AND DISCUSSION}

\section{Modelling using RSM Technique}

\section{ANOVA Analysis}

Statistical analysis of the experimental results pertaining to surface roughness and cutting force are carried out through the application of Analysis of variance (ANOVA) at 95\% confidence level (i.e. Significance level of 0.05). This would lead to evaluating the relative influence of each machining parameter on the responses [16, 17]. ANOVA results for arithmetic mean surface roughness $(R a)$ and cutting force $(F y)$ are illustrated in Table 4.

Table 4. Analysis of variance for: $a$ ) $R a$ and $b$ ) $F y$.

\begin{tabular}{|c|c|c|c|c|c|c|c|}
\hline Source & $D F$ & $S S$ & $M S$ & F-Value & $P$-value & C.\% & Signif \\
\hline \multicolumn{8}{|c|}{ a) Surface roughness (Ra) } \\
\hline Model & 7 & 8.02 & 1.145 & 13.452 & 0.0002 & 90.4 & Yes \\
\hline ap & 1 & 0.00 & 0.0032 & 0.037 & 0.8502 & 0.03 & No \\
\hline Tool & 1 & 0.62 & 0.616 & 7.24 & 0.0227 & 6.95 & Yes \\
\hline$V c$ & 1 & 0.00 & 0.0005 & 0.006 & 0.9385 & 0.006 & No \\
\hline$f$ & 1 & 7.11 & 7.107 & 83.467 & 0.0001 & 80.13 & Yes \\
\hline Tool $^{\wedge} 2$ & 1 & 0.11 & 0.114 & 1.344 & 0.2732 & 1.29 & No \\
\hline$V c^{\wedge} 2$ & 1 & 0.06 & 0.0568 & 0.667 & 0.4331 & 0.64 & No \\
\hline$f^{\wedge} 2$ & 1 & 0.12 & 0.119 & 1.404 & 0.2634 & 1.34 & No \\
\hline Resid & 10 & 0.85 & 0.085 & & & & \\
\hline Total & 17 & 8.87 & & & & & \\
\hline \multicolumn{8}{|c|}{ b) Cutting force $(F y)$} \\
\hline Model & 7 & 1229624 & 175661 & 5.40 & 0.0088 & 79.07 & Yes \\
\hline ap & 1 & 181116 & 181116 & 5.56 & 0.0400 & 11.65 & Yes \\
\hline Tool & 1 & 826267 & 286892 & 8.82 & 0.0141 & 53.13 & Yes \\
\hline$V c$ & 1 & 41371 & 41371 & 1.27 & 0.2859 & 2.66 & No \\
\hline$f$ & 1 & 85075 & 85075 & 2.61 & 0.1370 & 5.47 & No \\
\hline Tool $^{\wedge} 2$ & 1 & 58285 & 58285 & 1.79 & 0.2105 & 3.75 & No \\
\hline$V c^{\wedge} 2$ & 1 & 25109 & 25109 & 0.77 & 0.4004 & 1.61 & No \\
\hline$f^{\wedge} 2$ & 1 & 33477 & 33477 & 1.03 & 0.3344 & 2.15 & No \\
\hline Resid & 10 & 325458 & 32546 & & & & \\
\hline Total & 17 & 1555082 & & & & & \\
\hline
\end{tabular}


Table 4 ( $a$ ) displays the ANOVA results for the arithmetic mean surface roughness $(R a)$ and indicates that feed and tool type represent the dominant parameters affecting the surface roughness as their $P$-value is less than 0.05 than their larger $F$-value. Feed rate has the most important significant influence on surface finish with a contribution of $80 \%$. The second most significant parameter based on $F$-value is the tool type with 7.24 for $(R a)$ which is larger than the standardized $F$-table value (4.96) at the 5\% level of significance. It affects the roughness parameter $(R a)$ by $6.95 \%$. The other parameters (i.e. cutting speed and depth of cut) do not show any statistical influence on $(R a)$ because of their low contribution $(0.03 \%$ and $0.006 \%$ respectively). $P$-value is not less than 0.05 (i.e. larger P-value) and lastly calculated $F$ value is not more than $F$-table value.

For the cutting force $(F y)$, ANOVA results are indicated in Table $4(b)$. They show that the tool type affects $(F y)$ in a significant way $(53.13 \%)$, the next factor being the depth of cut with $11.65 \%$ contribution. The cutting speed and feed rate do not present any statistical significance on $(F y)$ because of their low contribution (2.66\% and $5.47 \%$ respectively).

\section{Regression Analysis}

The RSM technique is an empirical modelling approach developed for the determination of a relationship between various process parameters and responses. Its objective is to explore the influence of these parameters on responses and therefore optimize them [18-20]. In the present work, the RSM-based second-order mathematical model is expressed as:

$$
\delta=b_{0}+\sum_{i=1}^{k} b_{1} . \alpha_{i}+\sum_{i=1}^{k} b_{i i} \cdot \alpha_{i}^{2}
$$

where $\left(b_{0}\right)$ is the free term of the regression equation, and the coefficients $\left(b_{1}, b_{2} \ldots b_{k}\right)$ along with and $\left(b_{11}, b_{22} \ldots b_{k k}\right)$ are the linear and quadratic terms $[21,22]$. The empirical models expressed in the form of a quadratic regression equation that predicts the surface roughness and cutting force in terms of the depth of cut, tool type, feed rate and cutting speed are presented in Eqs. (2) and (3).

$$
\begin{aligned}
R a(\mu \mathrm{m})= & 1.543+0.107 \mathrm{ap}-0.904 \text { tool }-0.0047 \mathrm{Vc}-0.623 f \\
& +0.169 \mathrm{tool}^{2}+1.192 \times 10-5 \mathrm{Vc}^{2}+48.032 f^{2}
\end{aligned}
$$

$\left[\mathrm{R}^{2}=90.4 \%\right]$

$$
\begin{aligned}
F y(N)= & 519.672+802.476 a p-745.25 \text { tool }-2.520 V c+8242.51 f+ \\
& 120.712 \text { tool }^{2}+0.0079 V c^{2}-25412 f^{2}
\end{aligned}
$$

$\left[\mathrm{R}^{2}=79.07 \%\right]$

These equations are used to predict the response for given levels of each factor, and its accuracy can be evaluated. In the present case, $\left(R^{2}\right)$ is found equal to $90.4 \%$ for $(R a)$ and $79.07 \%$ for $(F y)$.

\section{Modelling using ANN technique}

Artificial neural network is usually more relevant to the prediction operations. It may be used as solution to the polynomial regression based modelling tool that provides the modelling of complex nonlinear relationships [23-25].

In this work two different ANN structures are applied for the surface roughness $(R a)$ and cutting force $(F y)$ with a different number of neurons in the hidden layer. The number of neurons in the input layer was fixed at four (depth of cut, tool type, cutting speed and feed rate) and the number of neurons in the output layer was fixed at one and represents either the response $(R a)$ or $(F y)$. A neuron or node is defined as a single processor calculation that sums up junctions and transfer functions. In addition and according to Hagan et al. [26], the information sent between neurons are represented by a change in weight $(w)$ and biases $(b)$.

The first step in the design of a neural network is designing its structure. It was herein set up as $\mathbf{4 - H}-\mathbf{1}$ thus describing the four input neurons representing the machining process variables (depth of cut, tool type, cutting speed and feed rate) with $(H)$ representing the number of neurons in a single hidden layer and (1) the output neuron describing the response investigated (surface roughness or cutting forces).

The optimal neural network structure was chosen on the basis of the optimal coefficient of determination $\left(R^{2}\right)$ and lower root mean square error (RMSE) between all architectures. This was performed through varying the number of neurons $(H)$ in the single hidden layer and consequently obtaining its value [27].

The experiments comprised two steps represented by a training session comprising 12 tests, and a validation integrating 6 tests with a leaning rate of (0.01). The activation function adopted is a hyperbolic tangent which is a sigmoid 
function. According to Sall et al. [28], the hyperbolic tangent $(\operatorname{Tan} H)$ results are comprised in the range [-1,+1]. It is expressed in Eq. (4) where $(x)$ is a linear combination of the $(X)$ variables.

$$
\operatorname{Tan} H=\frac{e^{2 x}-1}{e^{2 x}+1}
$$

\section{Surface Roughness Modelling}

Several network structures were tested (cf. Table 5). According to the determination coefficient and the root-meansquare error for training and validation tests, the adopted structure is 4-8-1 (Figure 2). It consists of four nodes in the input layer, corresponding to the number of cutting parameters, eight nodes in the hidden layer having a hyperbolic tangent transfer function form, and one node in the output layer having a linear transfer function form.

Table 5. Performance of ANN structures of $(R a)$ model.

\begin{tabular}{c|c|c}
\hline Inp_Hid_Oup & RMSE & $R^{2}$ \\
\hline 4_3_1 & 0.19 & 0.93 \\
4_4_1 & 0.37 & 0.74 \\
4_5_1 & 0.35 & 0.77 \\
4_6_1 & 0.28 & 0.85 \\
4_8_1 & $\mathbf{0 . 0 0 0 1}$ & $\mathbf{0 . 9 9}$ \\
4_9_1 & 0.22 & 0.91 \\
4_12_1 & 0.31 & 0.82 \\
\hline
\end{tabular}

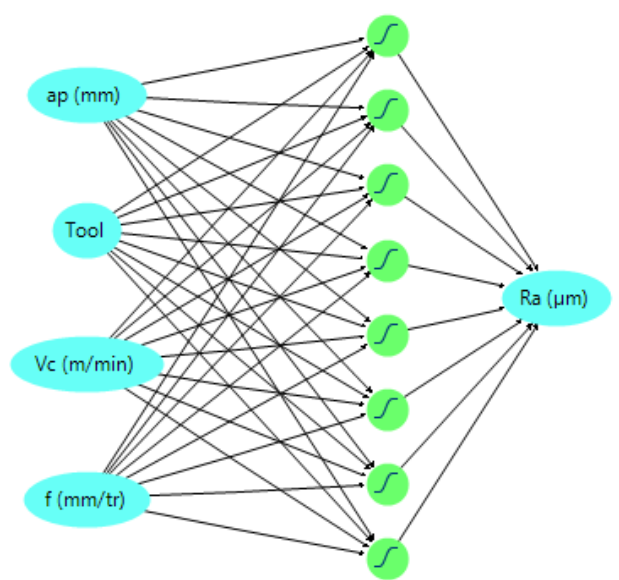

Figure 2. Neural structure chosen for $(R a)$.

The ANN model surface roughness is expressed by Eq. (5) with $R^{2}=90.4 \%$ :

$$
\begin{aligned}
R a(\mu m)= & -0.075 H_{1}-0.74 H_{2}+0.7 H_{3}+0.05 H_{5}- \\
& 1.22 H_{6}+0.3 H_{7}+0.2 H_{8}+2.1
\end{aligned}
$$

where,

$$
\begin{aligned}
& H 1=\tanh (0.5 \times(-12.980 \times a p-0.605 \times \text { Tool }+0.017 \times V c+2.448 \times f+2.746)) \\
& H 2=\tanh (0.5 \times(17.745 \times a p-0.532 \times \text { Tool }-0.018 \times V c+11.524 \times f-3.872)) \\
& H 3=\tanh (0.5 \times(-1.862 \times a p+1.055 \times \text { Tool }+0.019 \times V c+12.564 \times f-7.525)) \\
& H 4=\tanh (0.5 \times(-3.749 \times a p-0.150 \times \text { Tool }-0.005 \times V c+13.815 \times f+0.982)) \\
& H 5=\tanh (0.5 \times(-9.805 \times a p+0.906 \times \text { Tool }-0.009 \times V c-6.029 \times f+4.518)) \\
& H 6=\tanh (0.5 \times(-7.901 \times a p+1.714 \times \text { Tool }-0.0007 \times V c-11.410 \times f+3.691)) \\
& H 7=\tanh (0.5 \times(-7.230 \times a p-1.629 \times \text { Tool }-0.007 \times V c+6.681 \times f+5.365)) \\
& H 8=\tanh (0.5 \times(-1.500 \times \text { ap }-0.327 \times \text { Tool }-0.007 \times V c+56.004 \times f-5.026))
\end{aligned}
$$




\section{Cutting Force Modelling}

The same steps are considered for the modelling of the cutting force. The statistical results of the tested network structures are presented in Table 6. According to the determination coefficient and the root-mean-square error for both the training and validation tests, the adopted structure is 4-3-1. The chosen architecture for the ANN model is illustrated in Figure 3.

Table 6. Performance of ANN structures of $(F y)$ model.

\begin{tabular}{c|c|c}
\hline Inp_Hid_Oup & RMSE & $R^{2}$ \\
\hline 4_3_1 & $\mathbf{4 2 . 8 4}$ & $\mathbf{0 . 9 4}$ \\
4_4_1 & 64.15 & 0.87 \\
4_5_1 & 45.63 & 0.93 \\
4_6_1 & 69.24 & 0.85 \\
4_7_1 & 109.95 & 0.62 \\
4_8_1 & 81.87 & 0.79 \\
\hline
\end{tabular}

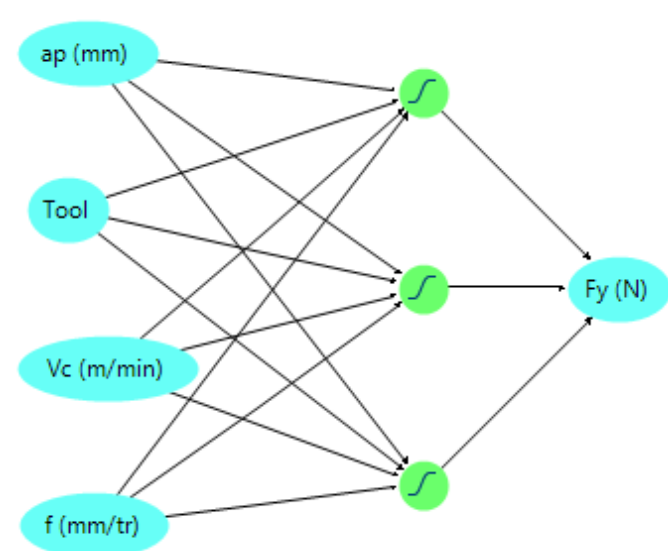

Figure 3. Neural structure chosen for $(F y)$.

The ANN model cutting force is expressed by Eq. (6) with $R^{2}=94 \%$ :

$$
F y(N)=-2758.18 \times H 1+1195 \times H 2-1387.52 \times H 3+1035.97
$$

where,

$$
\begin{gathered}
H 1=\tanh (0.5 \times(-4.784 \times a p+1.482 \times \text { Tool }-0.005 \times V c-6.366 \times f+2.975)) \\
H 2=\tanh (0.5 \times(-6.912 \times a p+2.238 \times \text { Tool }-0.008 \times V c-9.039 \times f+2.963)) \\
H 3=\tanh (0.5 \times(0.205 \times a p+0.0287 \times \text { Tool }+0.00049 \times V c-0.0088 \times f-1.1))
\end{gathered}
$$

\section{RSM and ANN Models Comparison}

In order to evaluate the accuracy of the fitting and prediction of the constructed models, coefficients of determination, performance function error analyses of root mean square error and model predictive error comparisons were carried out between the experimental and predicted data for both surface roughness and cutting force. The coefficients $\left(R^{2}\right),(R M S E)$ and $(M P E)$ were calculated as cited by Rajendra et al. [29] and García Gimeno et al. [30]. They are expressed in the equations below:

$$
R^{2}=\frac{\sum_{i=1}^{n}\left(y_{i, p}-y_{\text {average }}\right)^{2}}{\sum_{i=1}^{n}\left(y_{i, e}-y_{\text {average }}\right)^{2}}
$$




$$
\begin{gathered}
R M S E=\frac{\sqrt{\sum_{i=1}^{n}\left(y_{i, e}-y_{i, p}\right)^{2}}}{n} \\
\operatorname{MPE}(\%)=\frac{100}{n} \sum_{i=1}^{n}\left|\frac{\left(y_{i, e}-y_{i, p}\right)}{y_{i, p}}\right|
\end{gathered}
$$

where $(n)$ is the number of experiments, ; $\left(y_{i, e}\right)$ is the experimental value of the $\left(i^{\text {th }}\right)$ experiment, $\left(y_{i, p}\right)$ is the predicted value of the $\left(i^{\text {th }}\right)$ experiment determined by the model and $\left(y_{\text {average }}\right)$ is the average value of experimentally determined results.

Table 7 displays the comparison results of both $(R a)$ and $(F y)$ models developed by applying response surface methodology and artificial neural networks methods. In order to study and compare RSM and ANN models and determine which one can accurately predict surface roughness and cutting force, RSM and ANN models predicted results are plotted (Figure 4 and Figure 5) against the corresponding actual values.

Table 7. Comparison of RSM and ANN results.

\begin{tabular}{c|c|c|c|c|c|c}
\hline Responses & \multicolumn{3}{|c|}{$R a$} & \multicolumn{3}{c}{$F y$} \\
\hline Terms & $R^{2}$ & $M P E$ & RMSE & $R^{2}$ & $M P E$ & $R M S E$ \\
\hline RSM & 0.904 & 18.218 & 0.051 & 0.79 & 55.92 & 31.17 \\
ANN & 0.933 & 4.990 & 0.020 & 0.94 & 3.11 & 2.52 \\
Error & 0.029 & 13.228 & 0.031 & 0.15 & 52.81 & 28.65 \\
\hline
\end{tabular}

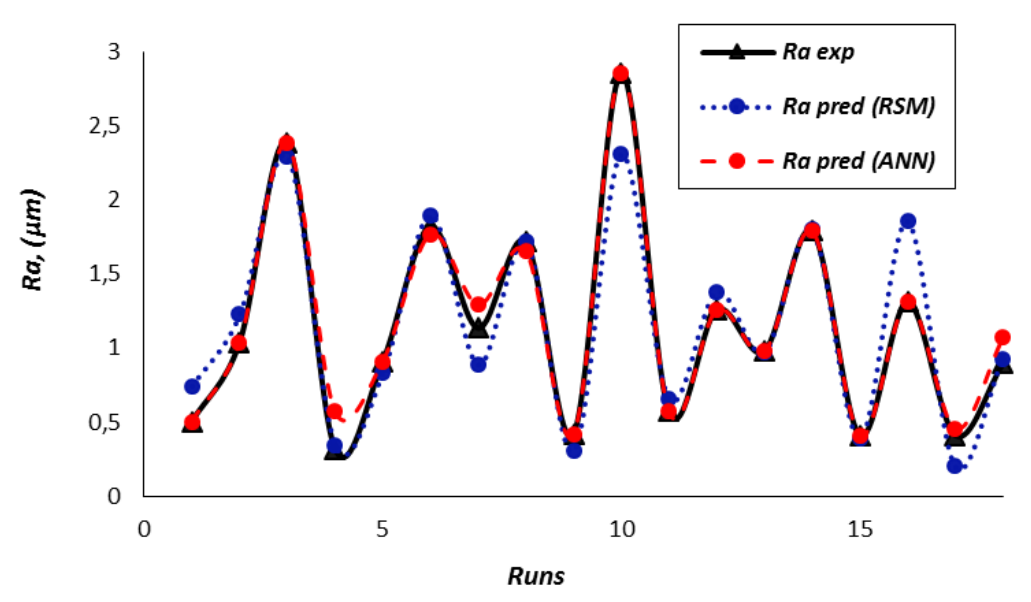

Figure 4. Experimental, RSM, and ANN predicted results for $(R a)$.

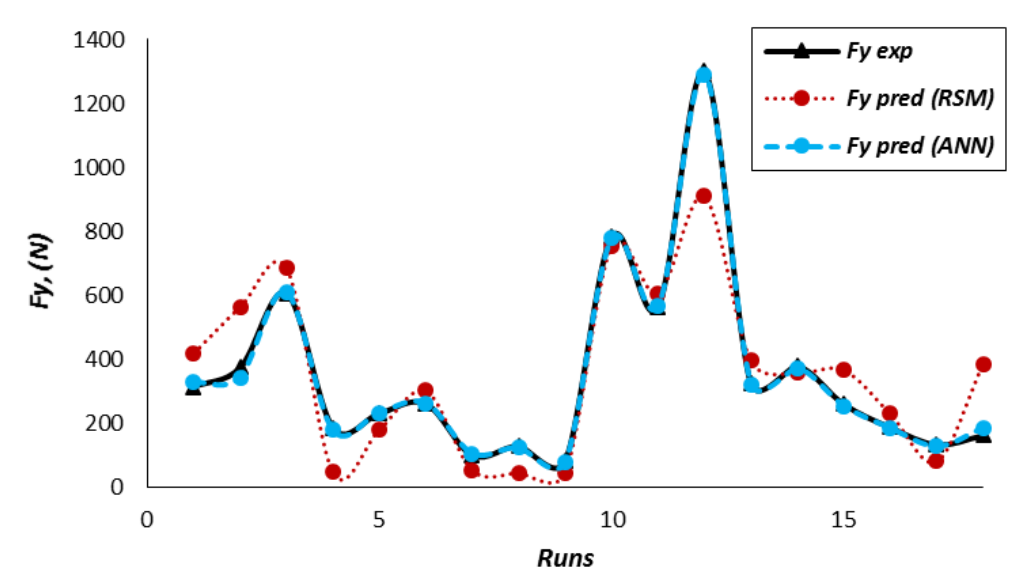

Figure 5. Experimental, RSM and ANN predicted results for $(F y)$. 
From Table 7 and Figures 4 and 5, it may be seen that the predicted values of the ANN models are closer to the experimental values than those of the RSM models. Three goodness metrics are usually used to evaluate the effectiveness of the developed models, and are represented by the determination coefficient $\left(R^{2}\right)$, the root mean square error $(R M S E)$ and the model predictive error $(M P E)$. Concerning $(R a)$, Table 7 shows that $\left(R^{2}\right), R M S E$, and $M P E$ for ANN models reach $93.3 \%, 0.02 \%$ and $4.99 \%$, respectively. They are found superior to those exhibited by RSM models $\left(R^{2}=0.4 \%\right.$, $R M S E=0.051 \%$ and $M P E=18.21 \%)$. Similar results are displayed for the cutting force $(F y)$ where the ANN models again demonstrate better results $\left(R^{2}=94 \%, R M S E=2.52 \%\right.$ and $\left.M P E=3.11 \%\right)$ compared to $\operatorname{RSM}\left(R^{2}=79 \%, R M S E=31.17 \%\right.$ and $M P E=55.92 \%)$. These results prove the robustness and reliability of the ANN technique and demonstrate the dependence of the surface roughness and cutting forces on the diverse cutting parameters. Consequently, the proposed ANN models pertaining to both surface roughness and cutting force will be employed as objective functions when carrying out the response optimization using the DFA technique.

\section{Optimization using DFA Technique}

The desirability function approach capable of simultaneously optimizing multiple responses was originally proposed by Derringer and Suich. It essentially translates the functions to a common scale $(0,1)$ then combines them using the geometric mean and finally optimizes the overall metric. DFA is usually preferred because of its ability to solve a multi response optimization problem by converting it into single response optimization one enabling the sorting out of the computational work [31-33]. The concept of desirability function involves the translation of the responses from their individual desirability to scale of composite desirability (overall desirability function). The DFA optimization process is used to perform through the following steps:

Step 1: Define the independent input parameters of the experimental design and the desired responses $\left(y_{i, p}\right)$ to be optimized.

Step 2: Adopt an experimental design plan and conduct experiments for the designed parameter combinations.

Step 3: Calculate individual desirability $(d i)$ for each response $\left(y_{i, p}\right)$ using desirability functions.

- $\quad$ Larger-the-Better: For the objective of finding out a maximum, the individual desirability is expressed as:

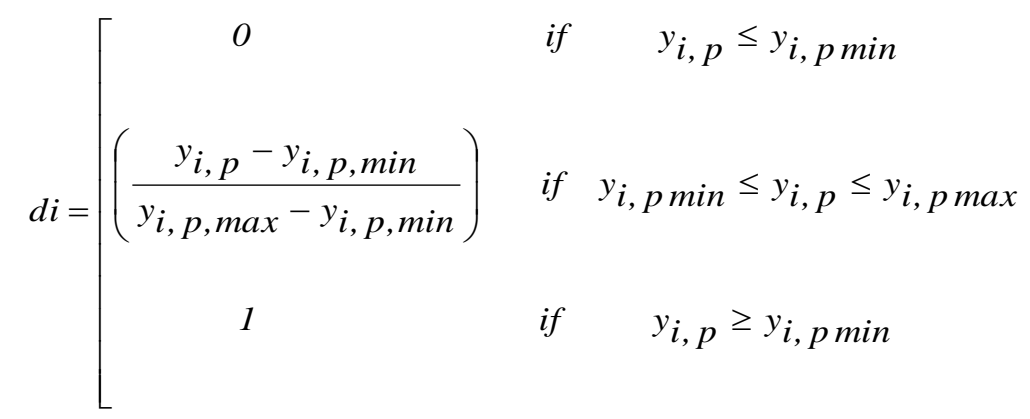

- $\quad$ Smaller-the-Better: For the objective of finding out a minimum, the individual desirability is expressed as:

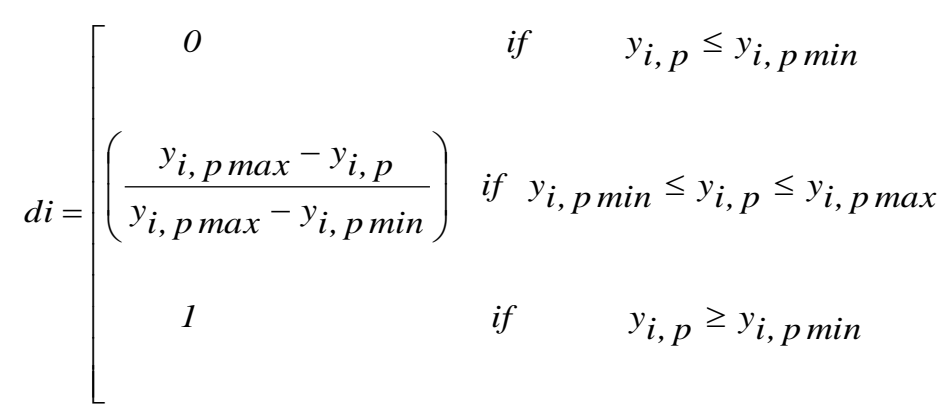

Step 4: Select the parameter combination that will maximize the composite desirability (Dc), and determine the optimal parameter and its level combination based on the higher value of composite desirability (Dc). 


$$
D c=\left(\prod_{i=1}^{p} d_{i}\right)^{\frac{1}{P}}
$$

where, $(d i)$ is the individual desirability of the response $(i),\left(y_{i, p}\right)$ is the predicted value of each response, $\left(y_{i, p \max }\right)$ and $\left(y_{i, p}\right.$ $\min$ ) is the max and the min value of each predicted response and $(P)$ is the number of response in the measure. The desirability ranges from zero to one.

\section{DFA Optimization for (Ra) and (Fy)}

During the optimization process, the aim was to find the optimal values of machining parameters in order to produce the lowest surface roughness and lowest cutting force $(R a$ and $F y)$. At first, the evaluation of individual desirability has been carried out for each response $\left(y_{i, p}\right)$ based on function Smaller-the-Better given in Eq. (11), which is used to minimize the response. Then, individual desirability of each response characteristics are fluxed into the composite desirability by using Eq. (12). As indicate previously, ANN models of surface roughness and cutting force are employed as objective function for response optimization. Table 8 shows the evaluated individual desirability and composite desirability values for each of the experimental trials.

Composite desirability has computed and the ranks are assigned to them in ascending order and it is found that the higher composite desirability value is $(D c=99.8 \%$ for both $R a$ and $F y)$ obtained for the $9^{\text {th }}$ trial of the experiment. The optimum cutting combination is $(a p 1-T o o l 3-V c 3-f 1)$ for $R a$ and $F y$. At this stage, the optimized machining parameters for minimizing surface roughness and cutting force in hard turning of AISI D3 steel are: cutting depth 0.25 $\mathrm{mm}$, Tool type 3 , cutting speed $300 \mathrm{~m} / \mathrm{min}$, and feed $0.08 \mathrm{~mm} / \mathrm{rev}$, with estimated surface roughness $R a=0.42 \mu \mathrm{m}$ and cutting force $F y=78.92 \mathrm{~N}$.

The contour plot of composite desirability has been plotted between the two most significant parameters $(f$ and Tool) by keeping the other terms constant as shown in (Figure 6). The multiple responses characteristic ( $D c$ ) found maximum where $f$ ranges from $0.08-0.16 \mathrm{~mm} / \mathrm{rev}$ with Tool type from $1-3$ for $R a$ and $F y$. This enclosed region indicates the optimum zone where $R a$ and $F y$ will be minimized.

Table 8. Evaluated individual desirability and composite desirability with their rank for $(R a)$ and $(F y)$.

\begin{tabular}{|c|c|c|c|c|c|c|}
\hline \multirow{2}{*}{ Runs } & \multicolumn{2}{|c|}{ ANN predicted value $\left(y_{i, p}\right)$} & \multicolumn{2}{|c|}{$\begin{array}{c}\text { Individual } \\
\text { desirability }(d i)\end{array}$} & \multirow{2}{*}{$\begin{array}{c}\text { Composite } \\
\text { desirability } \\
(D c)(\%)\end{array}$} & \multirow[b]{2}{*}{ Rank } \\
\hline & $\begin{array}{c}\text { Ra pred }(A N N) \\
(\mu \mathrm{m})\end{array}$ & $\begin{array}{c}\text { Fy pred }(A N N) \\
(N)\end{array}$ & $\begin{array}{l}R a \\
(\%)\end{array}$ & $\begin{array}{l}F y \\
(\%)\end{array}$ & & \\
\hline 1 & 0.51 & 327.21 & 0.96 & 0.80 & 0.874 & 5 \\
\hline 2 & 1.04 & 343.46 & 0.74 & 0.78 & 0.763 & 10 \\
\hline 3 & 2.38 & 610.49 & 0.19 & 0.56 & 0.330 & 16 \\
\hline 4 & 0.58 & 179.06 & 0.93 & 0.92 & 0.925 & 4 \\
\hline 5 & 0.91 & 232.68 & 0.80 & 0.87 & 0.833 & 6 \\
\hline 6 & 1.77 & 262.77 & 0.44 & 0.85 & 0.614 & 14 \\
\hline 7 & 1.29 & 105.12 & 0.64 & 0.98 & 0.791 & 8 \\
\hline 8 & 1.66 & 124.33 & 0.49 & 0.96 & 0.687 & 13 \\
\hline 9 & 0.42 & 78.92 & 1.00 & 1.00 & 0.998 & 1 \\
\hline 10 & 2.86 & 777.68 & 0.00 & 0.42 & 0.000 & 17 \\
\hline 11 & 0.57 & 566.29 & 0.93 & 0.60 & 0.747 & 12 \\
\hline 12 & 1.26 & 1290.47 & 0.65 & 0.00 & 0.000 & 18 \\
\hline 13 & 0.98 & 322.62 & 0.77 & 0.80 & 0.783 & 9 \\
\hline 14 & 1.79 & 372.56 & 0.44 & 0.76 & 0.574 & 15 \\
\hline 15 & 0.41 & 253.60 & 1.00 & 0.86 & 0.925 & 3 \\
\hline 16 & 1.31 & 184.34 & 0.63 & 0.91 & 0.760 & 11 \\
\hline 17 & 0.46 & 127.57 & 0.98 & 0.96 & 0.971 & 2 \\
\hline 18 & 1.07 & 185.79 & 0.73 & 0.91 & 0.815 & 7 \\
\hline
\end{tabular}




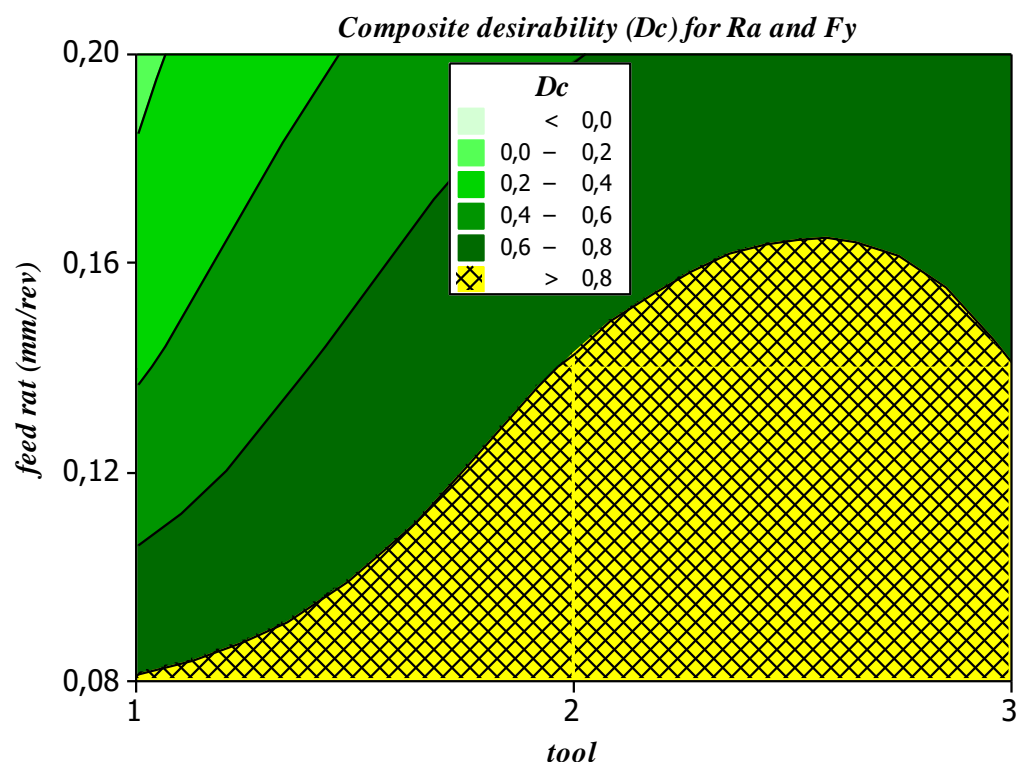

Figure 6. Contour plot of composite desirability $(D c)$ for $(R a)$ and $(F y)$.

\section{Confirmation of Optimization Results}

The predicted results based on the optimum level ( $a p 1-T o o l 3-V c 3-f 1$ for both $R a$ and $F y$ ) are evaluated and compared to associated experimental results in terms of percentage error. The errors are found to be within permissible limits, and Table 9 shows the maximum percentage error found equal to $2.94 \%$.

Table 9. Confirmation of optimization results.

\begin{tabular}{c|c|c|c}
\hline \multirow{2}{*}{ Responses } & Predicted & Experimental & Error \\
\cline { 2 - 3 } & $\left(\mathrm{ap}_{1}-\mathrm{Tool}_{3}-V c_{3}-f_{1}\right)$ & $\left(a p_{1}-\right.$ Tool $\left._{3}-V c_{3}-f_{1}\right)$ & $(\%)$ \\
\hline $\operatorname{Ra}(\mu \mathrm{m})$ & 0.42 & 0.42 & 0 \\
$F y(\mathrm{~N})$ & 78.92 & 81.86 & 2.94 \\
\hline
\end{tabular}

\section{CONCLUSIONS}

The present study carried out a comparison between both RSM and ANN techniques in terms of their modeling, prediction and generalization capabilities using the experimental data based on the Taguchi design for the surface roughness $(R a)$ and the cutting force $(F y)$. Determination of the optimum cutting conditions that lead to minimum surface roughness $(R a)$ and cutting force $(F y)$ are performed through the application of the DFA approach. The results achieved led to the following conclusions:

1. The ANOVA analysis proved the feed rate and tool type (with respective contributions of $80 \%$ and $6 \%$ respectively) are the most influential parameters of the surface roughness. Furthermore, the cutting force is significantly affected by the depth of cut and tool type with contributions of $11 \%$ and $53 \%$ respectively.

2. The (RSM) prediction model developed for $(R a)$ presents a coefficient of determination of 90.4 , a root mean square error of 0.051 and a model predictive error of $18.21 \%$. The (ANN) developed also for $(R a)$ presents a coefficient of determination of 93, a root mean square error of 0.020 and a model predictive error of $4.99 \%$. Concerning $(F y)$, coefficient of determination, root mean square error and the model predictive error were found to be 79.07, 31.17 and $55.92 \%$ for RSM and $94,2.52$ and $3.11 \%$ for ANN.

3. The comparisons undertaken led to conclude the ANN approach to be more precise in terms of the prediction of both the surface roughness and cutting force within the range of experiments performed. A better correlation and lower errors are drawn demonstrating the robustness and the reliability of the ANN technique. Consequently, the developed ANN models for both surface roughness and cutting force are adopted as objective function for the response optimization using DFA.

4. The Desirability Functional Approach is found to be most appropriate for dealing with multi-response optimization problems and leading to the optimal cutting conditions. The optimal cutting parameter combination for composite desirability achieved are apl-Tool3 $-V c 3-f 1$ which corresponds to cutting depth of $0.25 \mathrm{~mm}$, tool type 3 , cutting speed of $300 \mathrm{~m} / \mathrm{min}$, and feed rate of $0.08 \mathrm{~mm} / \mathrm{rev}$ for both $(R a)$ and $(F y)$.

5. From the confirmation results, it is shown that apl-Tool3-Vc3-f1 is the best parameter combination for surface roughness and cutting force with $2.94 \%$ accuracy. 


\section{ACKNOWLEDGEMENTS}

The present research study has been performed by the Metal Cutting Research Group, of the Structures and Mechanics Laboratory-LMS, of the 8 May 1945 - Guelma University, Algeria under the PRFU research project A11N01UN240120190001. The authors wish to acknowledge the contribution of the General Directorate of Scientific Research and Technological Development (DGRSDT) for their help and support.

\section{REFERENCES}

[1] H. Oktem, T. Erzurumlu, and F. Erzincanli, "Prediction of minimum surface roughness in end milling mold parts using neural network and genetic algorithm," Materials \& design, vol. 27, no. 9, pp. 735-744, 2006, doi: 10.1016/j.matdes.2005.01.010.

[2] A. Chabbi, M. Yallese, M. Nouioua, I. Meddour, T. Mabrouki, and F. Girardin, "Modeling and optimization of turning process parameters during the cutting of polymer (POM C) based on RSM, ANN, and DF methods," The International Journal of Advanced Manufacturing Technology, vol. 91, no. 5-8, pp. 2267-2290, 2017, doi: 10.1007/s00170-016-9858-8.

[3] K. Bouacha, M. A. Yallese, T. Mabrouki, and J.-F. Rigal, "Statistical analysis of surface roughness and cutting forces using response surface methodology in hard turning of AISI 52100 bearing steel with CBN tool," International Journal of Refractory Metals and Hard Materials, vol. 28, no. 3, pp. 349-361, 2010, doi: 10.1016/j.ijrmhm.2009.11.011.

[4] M. W. Azizi, S. Belhadi, M. A. Yallese, T. Mabrouki, and J.-F. Rigal, "Surface roughness and cutting forces modeling for optimization of machining condition in finish hard turning of AISI 52100 steel," Journal of mechanical science and technology, vol. 26, no. 12, pp. 4105-4114, 2012, doi: 10.1007/s12206-012-0885-6.

[5] B. Mallick, B. Sarkar, B. Doloi, and B. Bhattacharyya, "Analysis on the effect of ECDM process parameters during micromachining of glass using genetic algorithm," Journal of Mechanical Engineering and Sciences, vol. 12, no. 3, pp. 3942-3960, 2018, doi: 10.15282/jmes.12.3.2018.13.0344.

[6] H. Bensouilah, H. Aouici, I. Meddour, M. A. Yallese, T. Mabrouki, and F. Girardin, "Performance of coated and uncoated mixed ceramic tools in hard turning process," Measurement, vol. 82, pp. 1-18, 2016, doi: 10.1016/j.measurement.2015.11.042.

[7] H. Zahia, Y. Athmane, B. Lakhdar, and M. Tarek, "On the application of response surface methodology for predicting and optimizing surface roughness and cutting forces in hard turning by PVD coated insert," International Journal of Industrial Engineering Computations, vol. 6, no. 2, pp. 267-284, 2015, doi: 10.5267/j.ijiec.2014.10.003.

[8] H. Tebassi, M. A. Yallese, I. Meddour, F. Girardin, and T. Mabrouki, "On the modeling of surface roughness and cutting force when turning of Inconel 718 using artificial neural network and response surface methodology: accuracy and benefit," Periodica Polytechnica Mechanical Engineering, vol. 61, no. 1, pp. 1-11, 2017, doi: 10.3311/PPme.8742.

[9] A. Laouissi, M. Yallese, A. Belbah, S. Belhadi, and A. Haddad, "Investigation, modeling, and optimization of cutting parameters in turning of gray cast iron using coated and uncoated silicon nitride ceramic tools. Based on ANN, RSM, and GA optimization," The International Journal of Advanced Manufacturing Technology, vol. 101, no. 1-4, pp. 523-548, 2019, doi: 10.1007/s00170-018-2931-8.

[10] A. Zerti, M. A. Yallese, O. Zerti, M. Nouioua, and R. Khettabi, "Prediction of machining performance using RSM and ANN models in hard turning of martensitic stainless steel AISI 420," Proceedings of the Institution of Mechanical Engineers, Part C: Journal of Mechanical Engineering Science, vol. 233, no. 13, pp. 4439-4462, 2019, doi: 10.1177/0954406218820557.

[11] M. Nouioua, M. A. Yallese, R. Khettabi, S. Belhadi, M. L. Bouhalais, and F. Girardin, "Investigation of the performance of the MQL, dry, and wet turning by response surface methodology (RSM) and artificial neural network (ANN)," The International Journal of Advanced Manufacturing Technology, vol. 93, no. 5-8, pp. 2485-2504, 2017, doi: 10.1007/s00170017-0589-2.

[12] R. Kumar and S. Chauhan, "Study on surface roughness measurement for turning of Al 7075/10/SiCp and Al 7075 hybrid composites by using response surface methodology (RSM) and artificial neural networking (ANN)," Measurement, vol. 65, pp. 166-180, 2015, doi: 10.1016/j.measurement.2015.01.003.

[13] H. Aouici, M. A. Yallese, K. Chaoui, T. Mabrouki, and J.-F. Rigal, "Analysis of surface roughness and cutting force components in hard turning with CBN tool: Prediction model and cutting conditions optimization," Measurement, vol. 45, no. 3, pp. 344-353, 2012, doi: 10.1016/j.measurement.2011.11.011.

[14] V. Gaitonde, S. Karnik, M. Faustino, and J. P. Davim, "Machinability analysis in turning tungsten-copper composite for application in EDM electrodes," International Journal of Refractory Metals and Hard Materials, vol. 28, no. 2, pp. 221-227, 2010, doi: doi.org/10.1016/j.jirmhm.2009.10.002.

[15] H. Bouchelaghem, M. Yallese, T. Mabrouki, A. Amirat, and J. F. Rigal, "Experimental investigation and performance analyses of CBN insert in hard turning of cold work tool steel (D3)," Machining Science and Technology, vol. 14, no. 4, pp. 471-501, 2010, doi: 10.1080/10910344.2010.533621.

[16] N. Patil, K. Gopalakrishna, B. Sangmesh, K. Sudhakar, and G. Vijaykumar, "Performance studies on cryogenic treated carbide cutting tool for turning of AISI304 steel," Journal of Mechanical Engineering and Sciences, vol. 12, no. 3, pp. 3927-3941, 2018, doi: 10.15282/jmes.12.3.2018.12.0343.

[17] J. Pujara, K. Kothari, and A. Gohil, "An investigation of material removal rate and kerf on WEDM through grey relational analysis," Journal of Mechanical Engineering and Sciences, vol. 12, no. 2, pp. 3633-3644, 2018, doi: 10.15282/jmes.12.2.2018.10.0322. 
[18] L. Bouzid, M. A. Yallese, K. Chaoui, T. Mabrouki, and L. Boulanouar, "Mathematical modeling for turning on AISI 420 stainless steel using surface response methodology," Proceedings of the Institution of Mechanical Engineers, Part B: Journal of Engineering Manufacture, vol. 229, no. 1, pp. 45-61, 2015, doi: 10.1177/0954405414526385.

[19] D. M. D'Addona and S. J. Raykar, "Analysis of surface roughness in hard turning using wiper insert geometry," Procedia CIRP, vol. 41, pp. 841-846, 2016, doi: 10.1016/j.procir.2015.12.087.

[20] W. Lin, B. Lee, and C. Wu, "Modeling the surface roughness and cutting force for turning," Journal of Materials Processing Technology, vol. 108, no. 3, pp. 286-293, 2001, doi: 10.1016/S0924-0136(00)00835-9.

[21] I. Meddour, M. Yallese, R. Khattabi, M. Elbah, and L. Boulanouar, "Investigation and modeling of cutting forces and surface roughness when hard turning of AISI 52100 steel with mixed ceramic tool: cutting conditions optimization," The International Journal of Advanced Manufacturing Technology, vol. 77, no. 5-8, pp. 1387-1399, 2015, doi: 10.1007/s00170-014-6559-z.

[22] M. Elbah, M. A. Yallese, H. Aouici, T. Mabrouki, and J.-F. Rigal, "Comparative assessment of wiper and conventional ceramic tools on surface roughness in hard turning AISI 4140 steel," Measurement, vol. 46, no. 9, pp. 3041-3056, 2013, doi: 10.1016/j.measurement.2013.06.018.

[23] M. Ramezani and A. Afsari, "Surface roughness and cutting force estimation in the CNC turning using artificial neural networks," Management Science Letters, vol. 5, no. 4, pp. 357-362, 2015, doi: 10.5267/j.msl.2015.2.010.

[24] D. Lalwani, N. Mehta, and P. Jain, "Experimental investigations of cutting parameters influence on cutting forces and surface roughness in finish hard turning of MDN250 steel," Journal of Materials Processing Technology, vol. 206, no. 1-3, pp. 167179, 2008, doi: 10.1016/j.jmatprotec.2007.12.018.

[25] B. Samanta, W. Erevelles, and Y. Omurtag, "Prediction of workpiece surface roughness using soft computing," Proceedings of the Institution of Mechanical Engineers, Part B: Journal of Engineering Manufacture, vol. 222, no. 10, pp. 1221-1232, 2008, doi: 10.1243/09544054JEM1035.

[26] H. D. Beale, H. B. Demuth, and M. Hagan, "Neural network design," Pws, Boston, 1996.

[27] S. Dey and S. Chakraborty, "Forward and reverse mapping for WEDM process using artificial neural networks," Decision Science Letters, vol. 4, no. 3, pp. 277-288, 2015, doi: 10.5267/j.dsl.2015.4.008.

[28] J. Sall, A. Lehman, M. Stephens, L. Creighton, and S. S. JMP, "A Guide to Statistics and Data Analysis Using Jmp," SAS Institute, 2012.

[29] M. Rajendra, P. C. Jena, and H. Raheman, "Prediction of optimized pretreatment process parameters for biodiesel production using ANN and GA," Fuel, vol. 88, no. 5, pp. 868-875, 2009, doi: 10.1016/j.fuel.2008.12.008.

[30] R. García-Gimeno, C. Hervas-Martinez, R. Rodriguez-Perez, and G. Zurera-Cosano, "Modelling the growth of Leuconostoc mesenteroides by artificial neural networks," International journal of food microbiology, vol. 105, no. 3, pp. 317-332, 2005, doi: 10.1016/j.ijfoodmicro.2005.04.013.

[31] L. Bouzid, S. Boutabba, M. A. Yallese, S. Belhadi, and F. Girardin, "Simultaneous optimization of surface roughness and material removal rate for turning of X20Cr13 stainless steel," The International Journal of Advanced Manufacturing Technology, vol. 74, no. 5-8, pp. 879-891, 2014, doi: 10.1007/s00170-014-6043-9.

[32] H. Shahrajabian and M. Farahnakian, "Modeling and multi-constrained optimization in drilling process of carbon fiber reinforced epoxy composite," International Journal of Precision Engineering and Manufacturing, vol. 14, no. 10, pp. 18291837, 2013, doi: 10.1007/s12541-013-0245-1.

[33] K. Nabil, H. Zahia, M. Yalles, and N. Ouelaa, "Statistical analysis of surface roughness by design of experiments in hard turning," Mechanics, vol. 18, no. 5, pp. 605-611, 2012, doi: 10.5755/j01.mech.18.5.2704. 